\title{
THE DARK SIDE OF HURRICANE MATTHEW Unique Perspectives from the VIIRS Day/Night Band
}

\author{
Steven D. Miller, William C. Straka III, Jia Yue, Curtis J. Seaman, \\ Shuang Xu, Christopher D. Elvidge, Lars Hoffmann, and Irfan Azeem
}

The VIIRS Day/Night Band on Suomi NPP reveals key nocturnal aspects of the storm during its deadly traverse through the Caribbean and the U.S. eastern seaboard.

H urricane Matthew was by all measures the most powerful and devastating tropical cyclone (TC) of the 2016 Atlantic hurricane season (Stewart 2017). Matthew wreaked havoc across the central Caribbean and the southeastern United States between 28 September and 9 October 2016, leaving

AfFiliations: Miller AND SeAman-Cooperative Institute for Research in the Atmosphere, Colorado State University, Fort Collins, Colorado; STRAKA-Cooperative Institute for Meteorological Satellite Studies, University of Wisconsin-Madison, Madison, Wisconsin; YUE-Hampton University, Hampton, Virginia; $\mathrm{Xu}-$ Hampton University, Hampton, Virginia, and University of Science and Technology of China, Hefei, China; ElviDgE-National Oceanic and Atmospheric Administration/National Centers for Environmental Information, Boulder, Colorado; HoffManNJülich Supercomputing Centre, Forschungszentrum Jülich, Jülich, Germany; AzeEM-Atmospheric and Space Technology Research Associates, LLC, Boulder, Colorado

CORRESPONDING AUTHOR: Steven D. Miller, steven.miller@colostate.edu

The abstract for this article can be found in this issue, following the table of contents.

DOI:10.II75/BAMS-D-17-0097.I

In final form 24 June 2018

(C)2018 American Meteorological Society

For information regarding reuse of this content and general copyright information, consult the AMS Copyright Policy. widespread destruction in its wake. The storm's impacts on Haiti were particularly severe, where public reports estimated at least 546 lives were lost (an official total; unofficial estimates place the toll closer to 1,000); 240,000 homes were destroyed or severely damaged; and estimated damages approached \$1.9 billion. Damage to Cuba, including a bridge collapse that killed four people, was estimated at $\$ 2.6$ billion. A house collapse claimed four more lives in the Dominican Republic.

In the United States, Matthew claimed an additional 52 lives (34 direct and 18 indirect; Stewart $2017)$ and caused $\sim \$ 10$ billion in damages. Here, Matthew's impacts were most severe across coastal Georgia and the Carolinas, where coastal storm surge combined with inland flooding from torrential rainfall with accumulations in some areas exceeding 15 in. $(>380 \mathrm{~mm})$. The deluge inundated major urban corridors, causing widespread power outages across the coastal regions.

Officially, Matthew was responsible for over 600 deaths (585 direct, 18 indirect), and $\$ 15.1$ billion in estimated damages (Stewart 2017). At the time, Matthew stood as the ninth costliest Atlantic hurricane on record (based on a compilation of sources for storms dating back to 1965 , unadjusted for inflation or changes to population and wealth) - a ranking that, however significant, will certainly fall as 
damage assessments from Hurricanes Harvey, Irma, and Maria from the now infamous 2017 Atlantic hurricane season are finalized.

Environmental satellites play a critical role in the monitoring of TCs. From their vantage points on both geostationary (GEO) and low-Earth-orbiting (LEO) platforms, satellites offer a top-down perspective on these storms as they form and develop over the remote and inherently data-sparse tropical oceanic basins, well before they threaten land. The traditional demarcations between GEO and LEO satellite advantages reside along lines of resolution (spatial, spectral, temporal, and radiometric) and coverage. GEO satellites provide superior temporal resolution based on their ability to "hover" over locations within their hemispheric field of view, owing to their $\sim 35,786-\mathrm{km}$-altitude equatorial orbits selected to match exactly the rotation rate of Earth. As such, GEO satellites allow forecasters to watch the weather in motion, down to scales of 1-min refresh (Kalluri et al. 2018) via the latest generation of technology [e.g., the Geostationary Operational Environmental Satellite-R series (GOES-R); www.goes-r.gov]. LEO environmental monitoring satellites, flying in orbits around $650-850-\mathrm{km}$ altitude (or $\sim 50$ times closer to the Earth than GEO orbits), trade this high refresh rate for global coverage, higher spatial resolution, and a greater complement of spectral information, including cloud-probing passive microwave observations. The distinctions between LEO and GEO capabilities for visible and infrared imagery are beginning to blur with the introduction of next-generation sensors, such as the GOES-R Advanced Baseline Imager (ABI; Schmit et al. 2017).

The Day/Night Band (DNB; Miller et al. 2013) on the Visible Infrared Imaging Radiometer Suite (VIIRS) provides a unique kind of measurement that is rapidly establishing its value for TC monitoring. The first VIIRS DNB, part of a suite of five state-ofthe-art environmental sensors, flies on the National Oceanic and Atmospheric Administration (NOAA)National Aeronautics and Space Administration (NASA) Suomi National Polar-Orbiting Partnership (SNPP) satellite. Launched on 28 October 2011, SNPP has served as an operational risk reduction to NOAA's new-generation Joint Polar Satellite System (JPSS) program. The first JPSS satellite (JPSS-1, renamed NOAA-20 upon commission) was launched on 18 November 2017 and inserted into the same orbital plane as $S N P P$, improving the revisit time for the DNB. The DNB's claim to fame is its high sensitivity to very low-level visible and near-infrared light, enabling quantitative imaging of moonlit scenes and light emission from anthropogenic lights (e.g., cities), fires, and aurora, and other natural and artificial sources (Miller et al. 2013). The DNB draws its heritage from the Operational Linescan System (OLS), a low-light visible sensor that has flown on the Defense Meteorological Satellite Program (DMSP) since the late 1960s, with marked improvements to spatial and radiometric resolution.

A subset of the DNB's novel but less advertised capabilities were on full display during Hurricane Matthew, as the storm's most intense phase nested neatly within the part of the lunar cycle when the moon was not above the horizon at the time of night when SNPP overpasses ( 0130 local time). On such moonless nights, the DNB remains sensitive enough to observe clouds by the faint light of atmospheric nightglow and starlight (Miller et al. 2012b). On occasion, ripples of light can also be discerned in DNB imagery, revealing disturbances to the mesospheric nightglow layer, which link back to tropospheric storm dynamics (Miller et al. 2015). In the case of Hurricane Matthew, visible light information from both natural and artificial sources helped to reveal the DNB's nonlunar complement of nocturnal information-aspects of the DNB that are often overlooked. We consider this scope of DNB capabilities here, via a brief tale told from the "dark side" of Hurricane Matthew.

\section{CONVENTIONAL SATELLITE-BASED TC OBSERVATION. Conventional imaging radiom-} eters on board both LEO and GEO environmental satellite platforms, operating in the visible to thermal infrared parts of the electromagnetic spectrum (wavelengths ranging from about 0.4 to $15 \mu \mathrm{m}$ ), are staple to the operational TC forecaster, providing vital information on storm structure and intensity. The imagery exists on spatial scales ranging from the inner eyewall (subkilometer) to the broader (synoptic)-scale environment (thousands of kilometers). Such detail is very useful for estimating the storm's current location, level of organization, and key factors, giving insight to future changes in storm track and intensity.

GEO-based infrared measurements of cloud-top temperature (and particularly for an established TC, the gradient between the warmer eye and the surrounding cold cloud tops of the eyewall, correlating with the storm's minimum sea level pressure and maximum sustained winds) form the operational backbone to TC monitoring via the Dvorak method (e.g., Velden et al. 2006; Olander and Velden 2007). In addition, LEO-based capabilities such as passive microwave imagers and sounders provide analysts 
with complementary information critical to assessing storm structure and organization [e.g., overcoming visible (VIS) and IR limitations related to cloudobscured views of rainbands, eyewalls, and low-level circulations (LLC); Hawkins et al. 2001], both day and night. Nascent LEO measurements such as the DNB add a nighttime visible dimension to this expanding repertoire.

Radiation collected by imaging radiometers falls into the broad categories of visible (390-700 nm), near-infrared $(700 \mathrm{~nm}-1.4 \mu \mathrm{m})$, shortwave infrared (1.4-3 $\mu \mathrm{m})$, midwave infrared $(3-5 \mu \mathrm{m})$, and longwave (or "thermal") infrared (5-15 $\mu \mathrm{m}$ ). Traditionally, the sources of electromagnetic energy sensed in these spectral regions are demarcated by daytime (solar), nighttime (terrestrial), and combinations of the two. Imaging channels (or "bands") positioned in the visible through shortwave-infrared parts of the spectrum measure reflected sunlight. Midwave bands sense reflected sunlight during the day, and thermal emission from the surface and atmosphere both day and night. Thermal infrared bands measure only thermal emissions day and night. In some portions of the thermal infrared spectrum, atmospheric gases (e.g., water vapor, carbon dioxide, and ozone) are absorbing, while in other parts of this spectrum (principally $8-12 \mu \mathrm{m})$ the atmosphere is relatively transparent (called "atmospheric windows"). Whereas absorbing parts of the thermal infrared spectrum allow for characterization of atmospheric structure and its composition, the window regions enable imaging of the clouds and the surface. Thermal infrared atmospheric window bands (e.g., $\sim 11 \mu \mathrm{m}$ ) provide useful 24 -h TC imagery, enabling forecasters to routinely monitor the deep convection that provides a strong temperature contrast against the warmer ocean surface.

During the day, the strong signal of cloud-reflected sunlight, as measured in the visible band (e.g., $0.65 \mu \mathrm{m}$ ), typically affords higher spatial resolution imagery than the infrared-useful for highlighting details of storm-top structure and tracking low-level small clouds for atmospheric motion vector analyses (e.g., Velden et al. 2005). Additionally, the strong visual contrast between bright (reflective) clouds and the dark (absorbing) ocean, combined with the ability of visible light to transmit through cirrus clouds, which are more opaque at infrared wavelengths, provides a clearer and more complete description of lower-atmosphere clouds compared to the infrared. This helps forecasters infer the LLC center of tropical systems, which is useful for pinpointing storm location, determining surface impacts, and predicting changes to storm intensity.

\section{ON THE WEB}

Dr. Marshall Shepherd Forbes article on Hurricane

Matthew: www.forbes.com/sites/marshall

shepherd/2016/10/03/why-have-we-seen-a-blob-east-of

-hurricane-matthews-eye-and-why-it-should-concern-us/ \#4cbld2976bd3

National Hurricane Center track summary of Hurricane Matthew: www.nhc.noaa.gov/archive/20I6/graphics/all4 /loop_5W.shtml

Cooperative Institute for Meteorological Satellite Studies (CIMSS) satellite blog on DNB observations of Hurricane Matthew: http://cimss.ssec.wisc.edu/goes/blog/archives /date/2016/10/02

Without low-light sensitivity, visible-based analyses are limited to the daytime hours. The lack of visible light information over the course of the night can lead to a "sunrise surprise," (Landsea and Franklin 2013) when forecasters discover that the LLC of a tropical system (as revealed by the nowvisible low-cloud field) is in fact displaced from the mid- and upper-level circulation (tracked by colder clouds seen in the infrared) because of vertical wind shear. The magnitude of these displacements can sometimes extend to tens of kilometers, potentially affecting forecaster guidance for a TC near the coast (e.g., Hawkins et al. 2017).

SEEING IN THE DARK. The new generation of NOAA's LEO satellites is beginning to overcome the nocturnal information gap. The VIIRS DNB is a radiometer engineered specifically to detect very low levels of visible-to-near-infrared-spectrum (500-900 nm) light (Miller et al. 2013). The main value of this sensitivity is its ability to leverage unconventional sources of illumination, such as moonlight for imaging purposes; and its high sensitivity to light emissions, such as cities, ships, and fires. By extending certain "daytime" capabilities into the nighttime hours, it offers a new array of information that cannot be replicated by conventional infrared observations. The DNB has begun to shift the paradigm for nocturnal remote sensing in general. In the specific case of hurricanes, it provides additional insight into nocturnal storm properties and impacts.

Figure 1 (adapted from Hawkins et al. 2017) illustrates how the sunrise surprise was avoided in the case of Flossie, an eastern Pacific hurricane that threatened Hawaii as a tropical storm on 29 July 2016. The DNB's ability to reveal Flossie's LLC via 


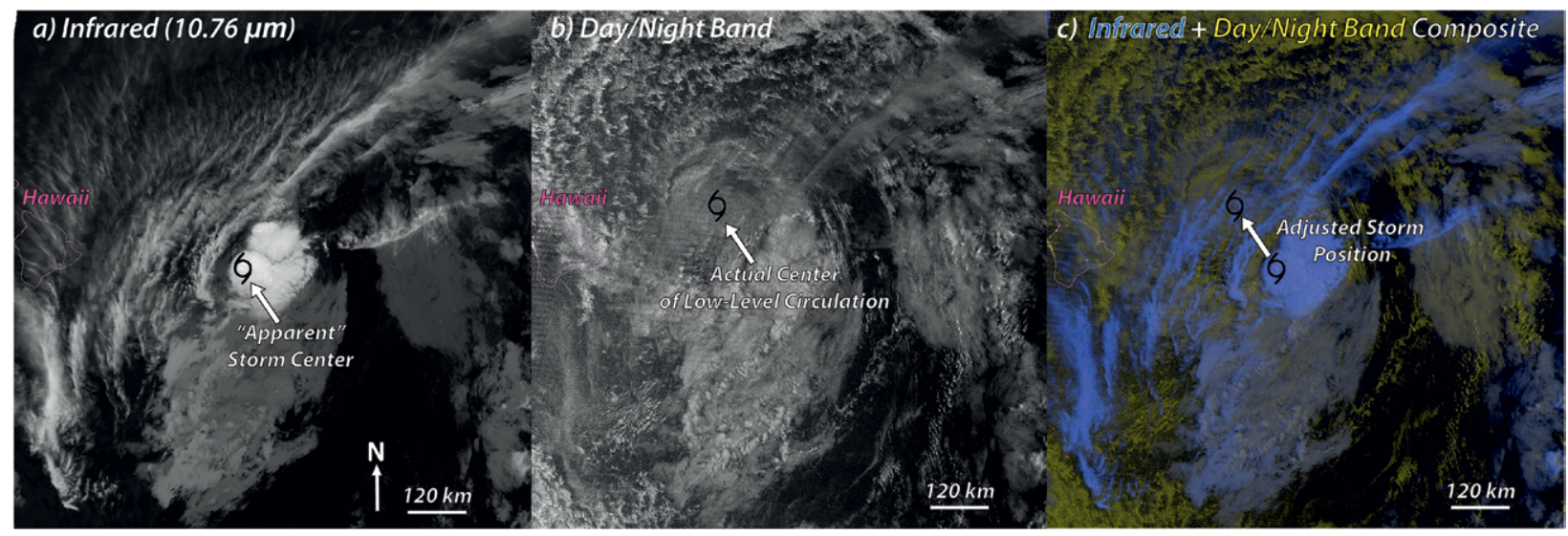

FIG. I. SNPP VIIRS imagery of Hurricane Flossie approaching the Big Island of Hawaii during the early morning hours ( IIO0 UTC, or 0100 local time) of $29 \mathrm{Jul} 2013$. (a) Infrared imagery shows an apparent storm center as indicated, based on the structure of cold cloud tops, (b) but the DNB moonlight reflectance imagery reveals that the LLC center is in fact displaced to the northwest. (c) The composite of the two images, with principal DNB information in yellow, shows how the strong vertical shear has decoupled the low-level and upper-level circulation of Flossie. Adapted from Hawkins et al. (2017).

moonlight reflection off the low-cloud field allowed forecasters at the Central Pacific Hurricane Center to modify their best track position, diminishing its forecasted threat to the Big Island of Hawaii. The focus of the current discussion on Hurricane Matthew is on the additional scope of capabilities available without the "luxury" of moonlight.

Figure 2 chronicles the track and intensity of Hurricane Matthew from the National Hurricane Center (Stewart 2017), overlaid with DNB imagery for eight consecutive nights on 1-8 October 2016 when Matthew was rated as a major hurricane (category 3 or greater on the Saffir-Simpson scale). The examples to follow illustrate the DNB's capability to examine the nocturnal light signals associated with Hurricane Matthew, including lightning connected to sprite formation, modulation of the atmospheric nightglow by storm-generated atmospheric gravity waves, and human impacts in terms of widespread power outages across the Carolinas. We preface this discussion with a brief recount of Matthew's life cycle and evolution into the most devastating storm of the 2016 hurricane season.

\section{MATTHEW'S EXTENSIVE PATH OF} DEVASTATION. Ostensibly, Matthew bore striking similarities to Hurricane Hazel (Gentry 1955; www.weather.gov/mhx/Octl51954EventReview), which in 1954 made landfall on 11 October over western Haiti as a category 4 hurricane, packing winds exceeding $135 \mathrm{mph}\left(\sim 60 \mathrm{~m} \mathrm{~s}^{-1}\right)$ and claiming an estimated 400-1000 lives). Like Matthew, Hazel went on to impact the southeastern U.S. seaboard states.
Matthew began as a strong tropical wave that entered the tropical Atlantic from the west coast of Africa on 23 September 2016. Moving rapidly [20-25 kt $\left.\left(1 \mathrm{kt} \approx 0.51 \mathrm{~m} \mathrm{~s}^{-1}\right)\right]$ across the equatorial Atlantic, the wave began to organize on 26 September. From there, it slowed and turned west-northwest. Matthew was named officially as a tropical storm on 28 September, during its westward transit through the southeastern Caribbean Sea, influenced by a strong ridge of high pressure to the north. It elevated to hurricane status in the afternoon (1800 UTC) of 29 September and rapidly intensified into a major hurricane only a day later.

For a 6-h period straddling the late evening and early morning hours of 30 September and 1 October, Matthew attained category 5 status (the highest level of the Saffir-Simpson hurricane wind scale), with peak 1-min sustained winds of $160 \mathrm{mph}\left(260 \mathrm{~km} \mathrm{~h}^{-1}\right)$ and a barometric pressure of $934 \mathrm{mb}(1 \mathrm{mb}=1 \mathrm{hPa})$. Shortly thereafter, Matthew weakened back to a category 4 hurricane (136-156 mph; 113-136 kt), completely stalled in its westward track by the evening of 1 October, and took a well-forecasted abrupt turn to the north. Matthew crept slowly northward over the next two days, approaching the heavily populated and highly vulnerable Tiburon Peninsula of Haiti. There, it made punishing landfall as a category 4 hurricane during the morning hours of 4 October. After clipping eastern Cuba later that evening, the storm crossed directly over the Bahamas (at category 3 to 4 intensities) and threatened the U.S. mainland.

Tracking northward over the next two days and weakening to category 3 strength, Matthew 
approached the east coast of central Florida in the late evening of 6 October. Matthew's recurvature track hugged the coastline from central Florida (causing a $\sim 2$-week delay in the launch of NOAA's new GOES-R satellite at Cape Canaveral) all the way along the southeastern U.S. seaboard with its eye remaining just offshore. By the time Matthew reached coastal Georgia on the evening of 7 October, it had further weakened into a category 2 hurricane, with $110-\mathrm{mph}$ (95 kt) sustained winds. At this latter stage, heavy rains and storm surge were the primary threats. After skirting the coastlines of North and South Carolina on 8 October, inundating coastal communities and causing widespread power outages along the way, Matthew's eastward trajectory into the open Atlantic ended its threat to the U.S. mainland.

Several noteworthy meteorological footnotes accompany Hurricane Matthew. Over a 24-h period between 0000 UTC 30 September and 0000 UTC
1 October, Matthew's winds increased by $75 \mathrm{kt}$, an extraordinarily rapid intensification that was, not surprisingly, missed by all the major operational models. In so doing, Matthew attained status as the southernmost category 5 hurricane in the Atlantic basin on record (Stewart 2017). During its most intense phase, Matthew produced an unusual amount of lightning, accompanied by prolific sprite production in the mesosphere above the storm. During its traverse of the southern Caribbean, the east side of Matthew exhibited an unusual, semipersistent "blob" of deep convection, reminiscent of a tropical mesoscale convective system (Fiolleau and Roca 2013), far removed from Matthew's center. Many of these features, which speak to both current and future storm intensity, are best observed from the vantage point of space. Here, the DNB provided a unique perspective on Matthew and its impacts by way of low-light sources from above and below.

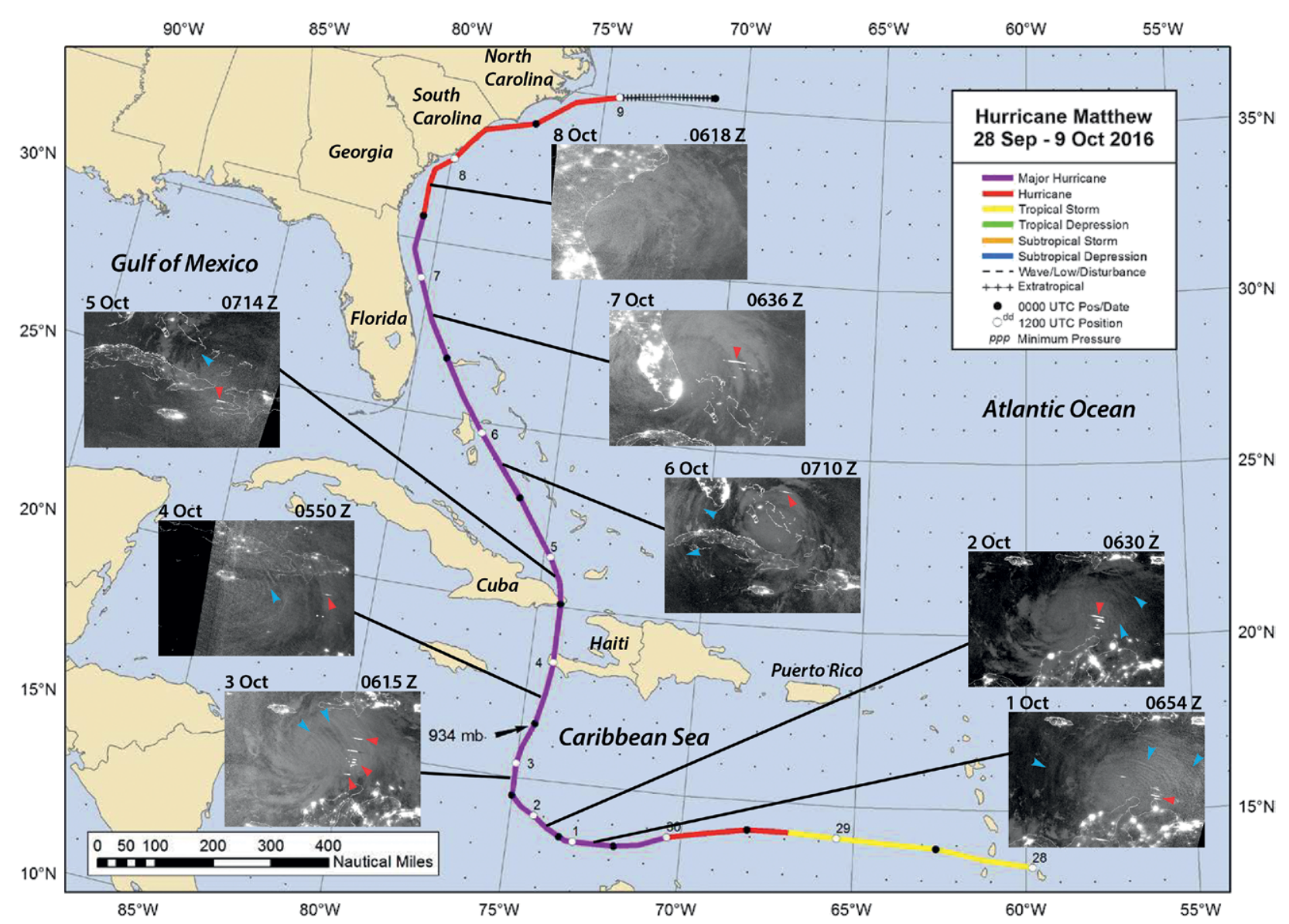

FIG. 2. National Hurricane Center track and intensity summary for Hurricane Matthew, overlaid with VIIRS DNB nighttime passes for an 8-day period when the storm was categorized as a major hurricane. Black lines connect the inset figures to the approximate storm location on the track for the date and time of each SNPP overpass. Red arrows on the images denote lightning flashes (horizontal white streaks), and blue arrows denote gravity waves (banded structures) via nightglow. Adapted from Stewart (20I7). 
NATURAL LIGHTS FROM ABOVE. Inspection of the DNB imagery in Fig. 2 reveals several notable attributes of Matthew. The most obvious features are clouds associated with the storm itself; isolated regions of brightness corresponding to city lights; and in a subset of the images (1-7 October), peculiar white segments overlying parts of the storm's eastern outer rainbands. The latter are how lightning flashes appear in DNB imagery-as the scanning sensor crosses over a flashing portion of the storm and captures the light escaping the cloud tops (e.g., Bankert et al. 2011). Although the DNB is not optimized for lightning detection, the observed flash segments contain limited information on flash frequency. When one or more adjacent DNB scan lines (separated in time by about $1.8 \mathrm{~s}$ ) contain flash signatures, it can be an indication of higher flash rates and more intense convection in that general location of the cloud complex.

Key to understanding DNB imagery is awareness of the available light sources, which can change significantly over time. For SNPP's $\sim 0130$ local crossing time, moonlight is not available for a 2 -week period of the 29.5 -day lunar cycle spanning from approximately two nights after last quarter, through the new moon, until two nights after the first-quarter lunar phase (Miller et al. 2012a). For the period spanning the life cycle of Matthew, the last quarter occurred on 23 September (Matthew became a named storm on 28 September) and the first quarter occurred on 9 October (Matthew lost its hurricane status on this day). Thus, the lunar cycle was not favorable for observing Matthew by way of moonlight-the principal light source for which the DNB was designed. Despite this seemingly worst-case observing scenario, it presented a golden opportunity to examine other forms of information present in DNB observations for an extensive series of moonless nights.

It is remarkable that Matthew's cloud structure can be seen at all in the imagery shown in Fig. 2, since there is no moonlight on these nights and thermal emissions are negligible in the DNB's spectral response. Here, the main source of light that reveals Matthew's cloud field comes from the sky itself, in the form of atmospheric nightglow (Miller et al. 2012b). These extremely low-level light emissions come from excited-state hydroxyls $\left(\mathrm{OH}^{\star}\right)$ and molecular oxygen originating primarily from a $\sim 10-\mathrm{km}$-thick layer near the mesopause ( $\sim 90 \mathrm{~km}$ above mean sea level). Other sources, including starlight, zodiacal light, and galactic light, provide contributions that are roughly one order of magnitude weaker than the atmospheric nightglow emissions in the DNB bandpass.
DNB nightglow signals are observable only on "moonless nights" of the lunar cycle; when the moon is above the horizon at even crescent moon phase, its light dominates the scene illumination. The character of DNB nightglow imagery is very different from its lunar counterpart. The weak emissions of nightglow are close to the noise floor of the DNB (i.e., where atmospheric light signals and instrument noise sources are of similar magnitude), imparting a "grainy" or "television static" appearance to the imagery compared to the sharp clarity of lunar night imagery. The diffuse, omnidirectional nightglow source negates cloud shadows that are formed by directional light sources like the moon or the sun. Given the highly scattering nature of clouds in the visible and near-infrared, nightglow imagery remains useful for revealing low-level clouds and clouds below cirrus, which pose detection issues for conventional thermal infrared imagery at night, providing forecasters with insight into the LLC associated with forming and dissipating TCs (Hawkins et al. 2017).

Careful inspection of Fig. 2 reveals another fascinating aspect of the nightglow measurements. Present in the same imagery as the lightning flashes (indicated by red arrows), and most notably on 1-6 October, are hints of alternating bright and dark banded features directly above and in regions surrounding Matthew. These banded structures (indicated by blue arrows in Fig. 2), which appear as ripples emanating from the TC, do not correlate with meteorological cloud patterns seen via reflected downwelling nightglow. They are in fact structures present in the upwelling emissions from the nightglow layer itself. The patterns are formed by atmospheric gravity waves (Holton 1982), launched by Matthew's convection. These waves perturb the temperature and density structure of the geometrically thin nightglow emission layer near the mesopause, modulating the brightness of the relatively laminar background field to form brightness patterns observable by the DNB.

As such, the DNB offers a unique windfall ability to resolve the finescale details of atmospheric gravity waves at subkilometer spatial resolution (Miller et al. 2015). Whereas the broad significance of these gravity waves to the general circulation of the atmosphere is well understood (Alexander et al. 2010), the practical applications of wave detection to the assessment and monitoring of TC intensity is a topic of active research (Hoffmann et al. 2018; Tratt et al. 2018).

Figure 3 shows thermal infrared $(10.763 \mu \mathrm{m})$ and DNB imagery for Matthew, honing in on the early morning hours of 1 October, about one day after Matthew had intensified to major hurricane status. 


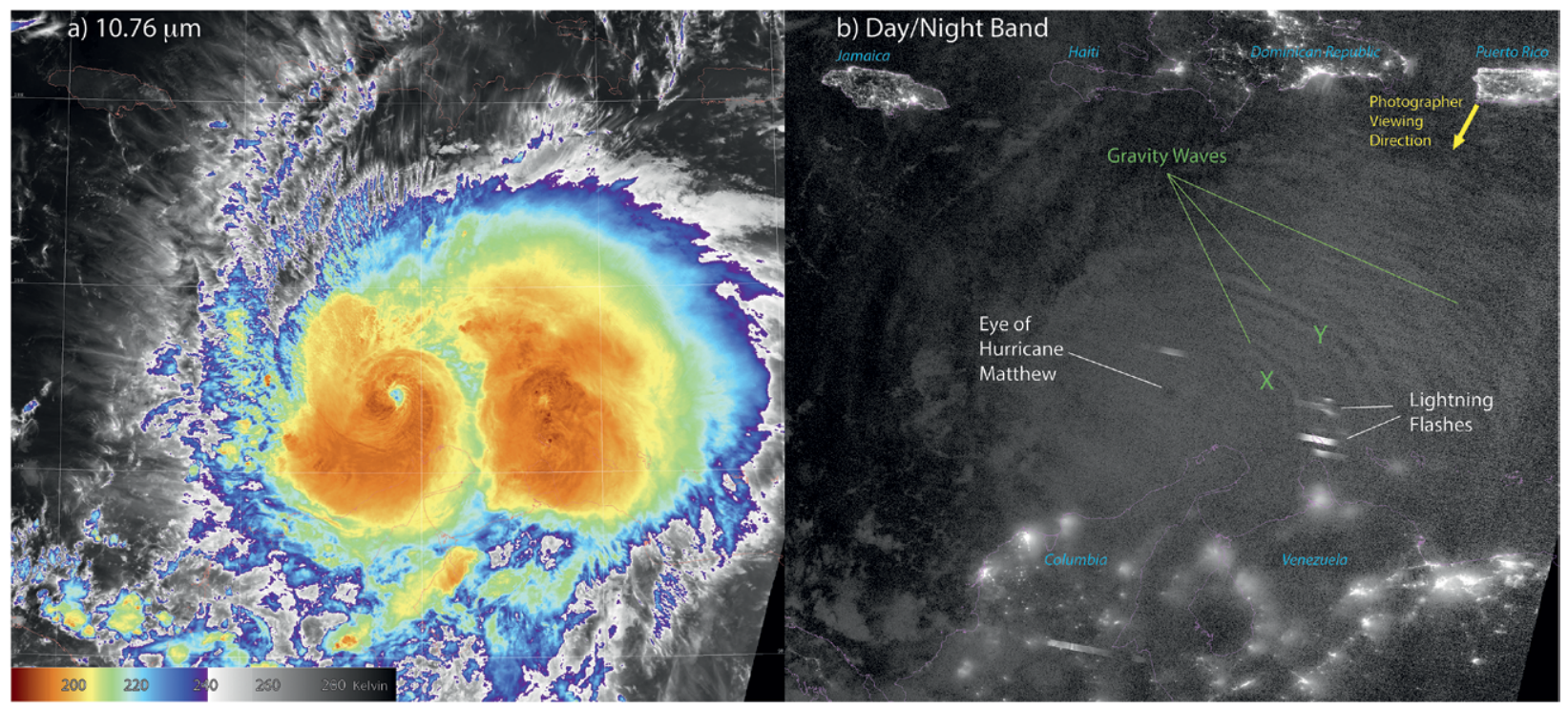

FIG. 3. VIIRS imagery of Hurricane Matthew, collected at 0651 UTC I Oct 20I6, contrasts the storm's varied appearance when viewed (a) in the thermal infrared $(10.763 \mu \mathrm{m})$ and (b) by the DNB (under nightglow/starlight illumination conditions). The $X$ and $Y$ markers in (b) correspond to locations where gravity wave properties were calculated.

Strong convection and associated cold cloud-top structures (Fig. 3a) in the blob of convection west of Matthew's eye correspond to lightning flashes noted in Fig. 3b. The DNB imagery shows a well-defined train of concentric waves in the northeast quadrant of the storm. These wave features are not present in the infrared (Fig. 3a) imagery, as they are not part of the meteorological cloud field.

The DNB imagery was analyzed to determine the approximate horizontal wavelength of the nightglow gravity waves. This estimate was conducted on a subset of waves located at the "X" and " $Y$ " markers in Fig. 3b. Traces, orthogonal to the wave structure, were averaged to form a sinusoidal pattern and were further smoothed via a 16-pixel boxcar averaging. The peak-to-peak distance in this sinusoidal pattern denoted the wavelength in terms of the number of pixels, and this value was multiplied by the DNB pixel resolution to attain the geometric wavelength. Following this procedure, the results for location $\mathrm{X}$ were $24-27 \mathrm{~km}$ and $30 \mathrm{~km}$ at location $\mathrm{Y}$, values falling within the range typically encountered in DNB imagery (Miller et al. 2015; Yue and Lyons 2015). These waves, of relatively short wavelength, propagate upward quickly (within $30 \mathrm{~min}$ to $1 \mathrm{~h}$ of their launching) from the troposphere to the mesosphere (Yue et al. 2013).

Thanks to citizen scientist and night-sky photographer Frankie Lucena, who happened to be capturing dramatic views of thunderstorm-induced sprites high above Matthew (well below the horizon from his vantage point in Cabo Rojo, Puerto Rico, as noted in Fig. 3b) within minutes of the SNPP overpass (Fig. 4), the DNB-indicated gravity wave features could be independently confirmed (Lyons 2017). Figure 4a shows both the gravity waves and sprites as seen from Lucena's surface-based vantage point. Similar nightglow wave patterns were also observed at the Arecibo Observatory in Puerto Rico. Whereas the surface perspective gives the appearance of plane waves, the satellite perspective of Fig. 3b reveals the broad-scale curvature of what is in fact a concentric wave pattern, as well as the full extent of the waves unobscured from the surface perspective by intervening meteorological clouds.

Following Yue and Lyons (2015), photogrammetry techniques supplied with knowledge of the photographer's reported geographic location $\left(18.05^{\circ} \mathrm{N}, 67.11^{\circ} \mathrm{W}\right)$, viewing direction $\left(212.54^{\circ}\right.$, south-southwest), altitude $(67 \mathrm{~m})$, and tilt angle $\left(5.44^{\circ}\right)$ were applied to the Lucena photo to estimate the wavelength of the faint nightglow gravity waves. The wavelength was calculated along the sinusoidal curve perpendicular to the wave front using a fast Fourier transform. Assuming a $90-\mathrm{km}$ wave altitude for these waves at the mesopause, this calculation yielded a wavelength of $\sim 30 \mathrm{~km}$, consistent with the DNB imagery-based estimates made at locations $X$ and $Y$ in Fig. 3b.

Using spherical geometry, the Lucena photo was projected onto a map to show the approximate location of sprites vis-à-vis DNB-observed convection 


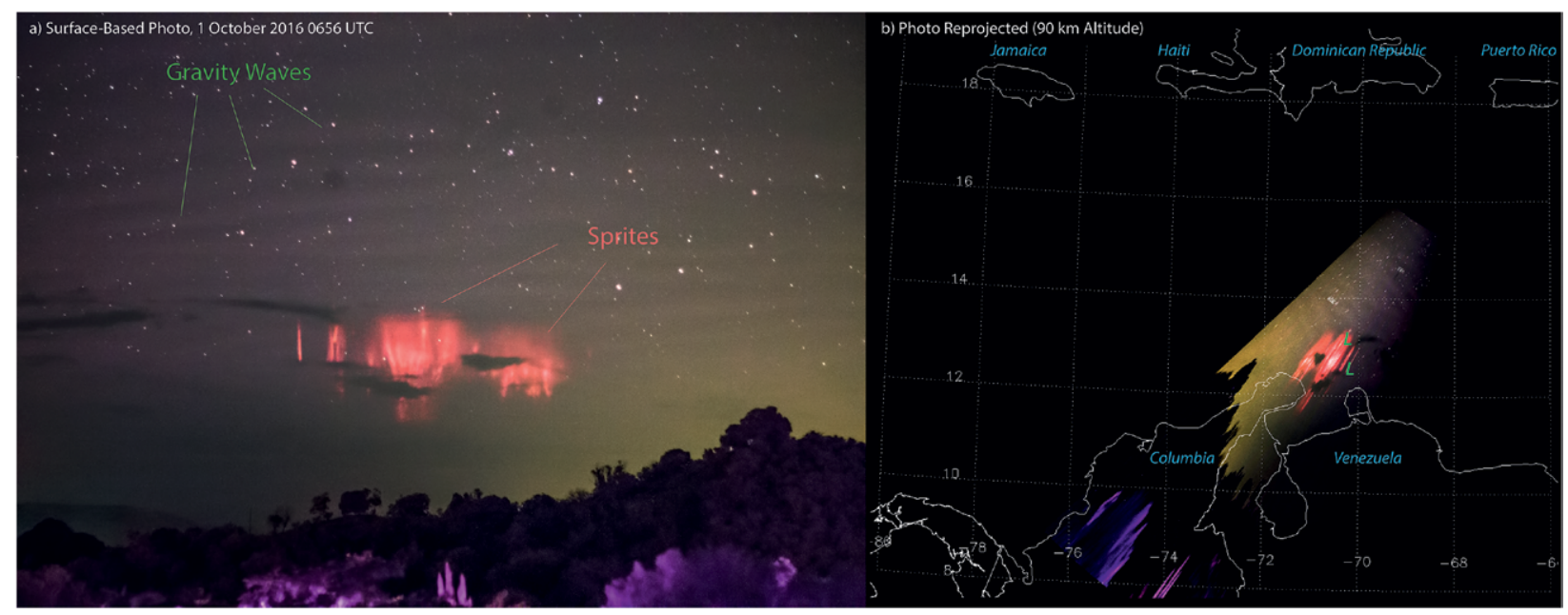

FIG. 4. (a) Surface-based nighttime photography (courtesy of Frankie Lucena) from Cabo Rojo, Puerto Rico, of the atmosphere above Hurricane Matthew at 0656 UTC I Oct 2016 (closely matched to Fig. 3). The southeastviewing photography captures both sprites and subtle bands of nightglow-demarcated gravity waves in the upper mesosphere. (b) The photo has been warped to a map using photographer location, altitude, viewing

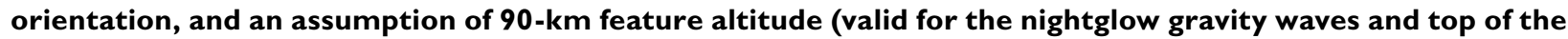
sprite complex). The sprite location (pink, north of Venezuela) aligns closely with the location of DNB-observed lightning flashes seen in Fig. 3b (and noted here with green L markers).

and lightning activity in Fig. 3. Assuming a sprite-top altitude of $90 \mathrm{~km}$ (W. Lyons 2017, personal communication), this remapping is shown in Fig. 4b. The upper portion of the photo (higher viewer elevation angles) comprises a narrower field of view closer to the photographer's location, and lower portions of the photo correspond to progressively wider fields of view and extended ranges. This transformation imparts a stretching effect to the remapped photo. In addition, the photo is flipped from how it appears in Fig. $4 \mathrm{a}$, since the right side of the original photo corresponds to western parts of the scene and the left side to eastern parts of the scene. Because the entire sprite structure was assumed to be located at $90-\mathrm{km}$ altitude for the purposes of the photo reprojection, when in fact the sprites are vertically extensive (with lower portions around $50 \mathrm{~km}$ ), the actual nadir location of the sprite complex is near the northeastern edge of the mapped sprite structure.

With these interpretive caveats in mind, Fig. $4 \mathrm{~b}$ shows that the sprites occurred in the same general location as the cluster of DNB-observed lightning flashes shown in Fig. 3b, offshore of Venezuela (locations marked with "L"). This region of enhanced flash activity corresponds to the previously noted stationary band (or blob) of convection seen in Fig. 3a, thought to be formed in part by convergence between the easterly trade winds and the west-southwesterly circulation of Matthew, and possibly by other processes (described in Willoughby et al. 1984).
The gravity waves seen in Fig. 4a are remapped in Fig. $4 \mathrm{~b}$ to a location just north of the sprites. The location and orientation of these waves is consistent with the DNB-observed concentric gravity wave patterns shown in Fig. 3b, located just to the northwest of the lightning flash cluster. Based on the understood physics of gravity wave launching and propagation (Holton 1982; Alexander et al. 2010), and previous examples of thunderstorm-induced wave structures (e.g., Dewan et al. 1998; Yue et al. 2009, 2013; Miller et al. 2015), the most likely forcing mechanism for these waves was the blob of strong convection located just to the east of Matthew. The availability of sprite and gravity wave photography at just the time of the SNPP overpass provided a serendipitous opportunity to link DNB atmospheric light emissions to a form of ground truth.

The full vertical extent of the atmosphere above and for a wide region around Matthew felt the storm's presence, as convectively induced gravity waves propagated upward and outward through the stratosphere, mesosphere, and ultimately into the ionosphere. The waves seen in DNB nightglow imagery are best understood as a cross-sectional snapshot of what is in fact a four-dimensional (space/time) varying spectrum of gravity waves throughout the atmospheric column. Nearly concurrent observations (not shown here) from the Atmospheric Infrared Sounder (AIRS) on NASA's Aqua satellite detected concentric waves in the form of temperature perturbations at $\sim 4.3 \mu \mathrm{m}$ 


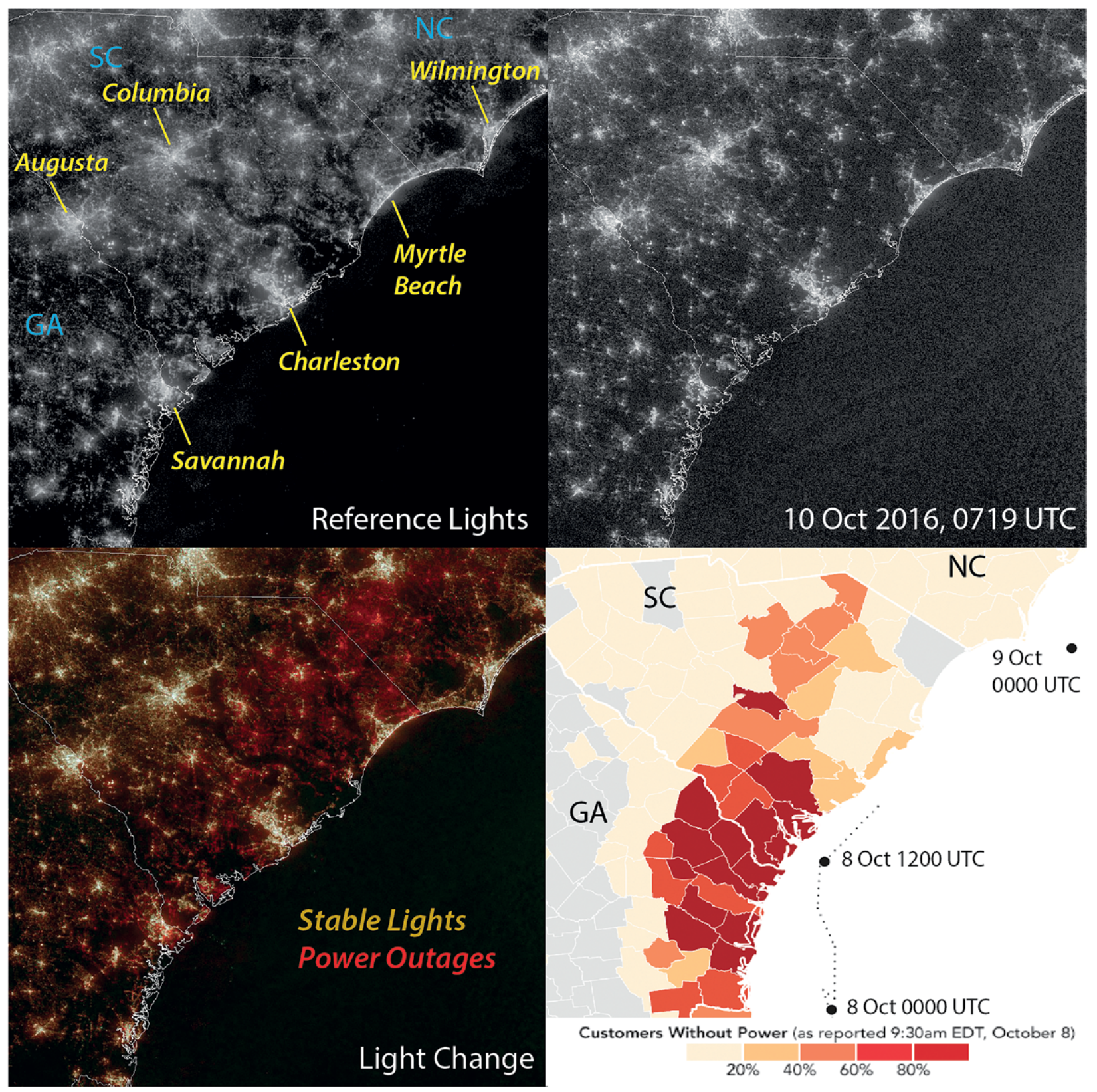

FIG. 5. (top left) Reference city lights composited from a year of DNB data, showing the cloud-free distribution of lights. (top right) DNB observations at 0719 UTC 10 Oct 2016 in the wake of Hurricane Matthew's passage, showing reduced lighting compared to the reference image. (bottom left) Enhancement imagery showing differences between the reference and 10 Oct imagery, with inferred power outages shown in red. (bottom right) Power outage information compiled from region utility services valid on the morning of 8 Oct 2016 (roughly $40 \mathrm{~h}$ prior to the DNB imagery shown), showing the distribution and severity of outages reported at that time and how the outages have shifted to the northeast (courtesy of Joshua Stevens, NASA Earth Laboratory).

in the midstratosphere $(\sim 40 \mathrm{~km}$; e.g., Hoffmann et al. 2018; Tratt et al. 2018), while a continental U.S. surface-based total electronic content (TEC) array measured similar concentric wave patterns in the lower ionosphere (90-400 km; e.g., Azeem et al. 2015), as the waves induced collisional interactions in the plasma.
The so what? implications of detecting gravity wave features in DNB imagery span several dimensions as well. In the broadest sense, gravity waves are a fundamental form of energy transfer, and through their breaking or dissipation at different altitudes they deposit their momentum and energy into the background flow. In so doing, they govern 
key dynamical processes of the middle and upper atmosphere, some of which feed back to influence our tropospheric weather patterns on seasonal and longer-term time scales. Despite their importance, there are very few direct measurements of gravity waves, especially at the fine spatial scales resolved by the DNB. Instead, climate models must rely on crude parameterizations of gravity wave effects, giving rise to uncertainties that grow with time (Alexander et al. 2010).

Given the relative infrequency and limited spatial extent of TC-generated gravity waves, they are not likely to play an important role in the general circulation. However, what these waves communicate in terms of storm dynamics, and specifically in terms of storm intensity assessment and prediction, is a subject of growing interest on the cutting edge of scientific inquiry. The basic relationship between TC intensity and stratospheric gravity wave activity has been demonstrated (Miller et al. 2015) and empirically established (Hoffmann et al. 2018), leading to suggestions for new geostationary-based, AIRS-like satellite observing systems (measuring temperature perturbations in the $\mathrm{CO}_{2}$ absorption band near $4.3 \mu \mathrm{m}$ ) dedicated to the continuous monitoring and characterization of gravity waves (Tratt et al. 2018).

ARTIFICIAL LIGHTS FROM BELOW. One of the key capabilities of low-light visible observations is the ability to observe the "human footprint" directly, by way of artificial lights. Detection of power outages, predicated on changes in these lights against a background reference of stable light sources, was first established for low-light visible observations from the DMSP OLS (e.g., Elvidge et al. 1998; Kohiyama et al. 2004; Witmer and O'Loughlin 2011). This same approach has been extended to the higher-resolution DNB observations in recent years (e.g., Cao et al. 2013; Folmer et al. 2015), and is demonstrated here for Hurricane Matthew.

By the time Matthew had reached the southeastern United States, it had decreased significantly in its intensity compared to when it ravaged the Caribbean, and the main threats from the diminished storm came in the form of intense rainfall [10-19 in. ( 254$483 \mathrm{~mm}$ ) accumulation in parts of the Carolinas], a moderate storm surge [maximum values in the range of $6-7 \mathrm{ft}(1.8-2.1 \mathrm{~m})]$ and associated coastal flooding. These factors, combined with 60-70-kt sustained winds and 80-kt gusts as the storm skirted the coast, produced widespread damage and caused power outages across the region. Outages affected nearly 3 million customers along the east coast of Florida and the coastal Carolinas. When the clouds associated with Matthew's passage finally cleared, nighttime DNB observations of changes to city lights provided a unique perspective on the distribution of power outages across the region.

Figure 5 compares the relatively clear-sky view of city lights during the early morning of 10 October 2016 to a background reference of stable lights compiled from a full year (2013) of historical DNB data (Elvidge et al. 2017). The stable lights database was produced by the National Centers for Environmental Information (NCEI). A simple red-green-blue (RGB) composite imagery technique was used to consolidate the light-change information into a single visually intuitive graphic. To produce this imagery, we first took the logarithm of the city light radiances ( $\mathrm{W} \mathrm{cm}^{-2} \mathrm{sr}^{-1}$ ) and normalized the values between a scaling range of $\left(\min _{\mathrm{scl}}, \max _{\mathrm{scl}}\right)=(-9.5,-6.5)$, done for both the reference and the current DNB scene radiances ( $L_{\text {refer }}$ and $L_{\text {curr }}$ respectively):

$$
\begin{aligned}
L_{\text {refer }, \mathrm{N}} & =\left(L_{\text {refer }}-\min _{\text {scl }}\right) /\left(\max _{\text {scl }}-\min _{\text {scl }}\right) L_{\text {curr }, \mathrm{N}} \\
& =\left(L_{\text {curr }}-\min _{\text {scl }}\right) /\left(\max _{\text {scl }}-\min _{\text {sc }}\right) .
\end{aligned}
$$

Values below (above) the scaling range were set to 0 (1). The RGB color guns were then defined using the normalized quantities from Eq. (1) as follows:

$$
\begin{aligned}
& \mathrm{R}=\left(L_{\text {refer }, \mathrm{N}}\right)^{0.75}, \\
& \mathrm{G}=\left(L_{\text {refer } \mathrm{N}}\right)^{0.75,} \\
& \mathrm{~B}=\left(L_{\text {refer }, \mathrm{N}}\right)^{0.75} .
\end{aligned}
$$

These color guns were then multiplied by 255 , converted to byte values, and combined to form the final "power outage RGB."

Determined experimentally and based on simple manipulation of the RGB color space, the qualitative effect this nonlinear scaling has on the product imagery is to produce red coloration where the reference imagery is brighter than the current imagery (denoting a possible outage), golden coloration where the reference and current imagery are similar (and giving the appearance of sodium lamps, common to U.S. cities), and a green coloration wherever the current imagery is brighter than the reference (e.g., new lights associated with search and rescue operations, or enhanced scene reflectance arising from any moonlight present in the current image).

Interesting details emerge upon close inspection of the power outage RGB produced via Eqs. (1) and (2). The main power outages appear to affect suburban 
areas, and sharp discontinuities exist in some areas. This does not imply that outages do not exist in the urban zones, given the increased probability of some light occurring in these denser-population areas at the DNB subpixel scale. The state boundary between the Carolinas shows significant outages to the south and less impact to the north. It is likely that such prominent discontinuities in outages are the result of variable storm impacts to different power grids. The $742-\mathrm{m}$ resolution of the DNB is seen here to be sufficient in delineating outage impacts on these spatial scales.

Because intervening cloud cover causes a reduction and diffusion of surface lights, this RGB method may produce coloration artifacts (false alarms) arising as a result of clouds present in the current image. Also, when using this method during the part of the lunar cycle where moonlight varies from night to night, one must enlist a surface reflectance database (e.g., Román et al. 2018) coupled to a lunar irradiance model (e.g., Miller and Turner 2009) to predict and account for the changing scene radiance. Not doing so would impart either a green or red undertone bias to the RGB imagery per the scheme of Eqs. (1) and (2), depending on whether the moon was in the waxing or waning part of its cycle, respectively.

Included in Fig. 5 is an analysis of power outages, stratified by county, valid on the morning of 8 October (approximately 1.5 days prior to DNB imagery), for approximately the same region shown in the DNB images. These data came from a variety of utilities: Duke Energy, Florida Power and Light Company, Georgia Power, South Carolina Electric and Gas. Unfortunately, additional outage data from these sources were not available to enable a better time match with the DNB, and extensive cloud cover precluded power outage RGB imagery on earlier nights. At the time of this analysis, Matthew was still offshore of Georgia, and this is reflected in the bulk of the reported outages being in coastal Georgia and southern parts of South Carolina. Notably, these same areas appear to have recovered substantially (golden lights in the DNB RGB image) by the time of the early morning on 10 October DNB imagery shown in Fig. 5, whereas counties to the north, appearing prominently in red (outages) in the DNB power outage RGB image, had not yet felt the impacts of Matthew at the time of the outage report.

SUMMARY, AND LOOKING AHEAD. Whereas the VIIRS DNB was designed principally with moonlight imagery applications in mind, the main impacts of Matthew occurred during a portion of the lunar cycle without moonlight at the time of the SNPP overpass. These conditions provided an opportunity to showcase the additional capabilities of DNB observations in nonlunar nocturnal environments-probing the darkness to reveal cloud fields by the faintest of natural light sources, shedding new light on the poorly understood inner workings of TC dynamics with possible linkages between nightglow gravity waves and elusive intensity forecast improvements-while also offering unique perspectives on the aftermaths of storm impacts to human infrastructure. The epiphany here is that even on the darkest of nights there is still useful information to be had from DNB observations; with an instrument as sensitive as the DNB, both figuratively and literally we are never truly in the dark.

For all its potential benefits, the Achilles' heel of the DNB in terms of operational utility lies in its relative infrequency compared to geostationary observations. VIIRS provides a single snapshot at $\sim 0130$ local time [descending node, and a corresponding daytime pass at 1330 local time, ascending node (LTAN)], precluding the ability to analyze storm dynamics. The capability has improved with the addition of JPSS-1, launched successfully on 18 November 2017 and renamed officially as NOAA-20 upon reaching polar orbit. NOAA-20, part of the JPSS series, includes a VIIRS DNB sensor like the one on SNPP. Placed onehalf orbit ahead of $S N P P$, in the same orbital plane, the tandem satellites observe the same location (where their swaths overlap) within $\sim 50$ min of each other.

The dual-DNB views should be useful for many aspects of TC nocturnal monitoring, including those highlighted in this study. In terms of cloud detection (both via moonlight and nightglow/starlight), the dual observations can be used to compute cloud motion vectors. The ability of the DNB to peer through optically thin cirrus and detect low clouds will thereby provide enhanced LLC assessments. In terms of nightglow gravity wave characterization, the dual observations can provide new details on wave motion and an ability to better relate these waves to key morphological changes linking to changes in TC intensity. However, a 50-min imagery pairing is likely too coarse to resolve phase velocities for convectively forced gravity waves, which typically exhibit periods on the order of 10-15 min. Power outage monitoring benefits from multiple views will increase the chances of a clear-sky line of sight to the surface. In this context, a 50-min separation is useful, as it increases the decorrelation of the ephemeral cloud field between the two observing times compared to a shorter separation time. 
The insertion of NOAA-20 into the same orbit as $S N P P$ is not part of a broader strategy to increase temporal resolution for measurements such as the DNB. Rather, it is keeping with an international satellite coordination agreement [the Initial Joint Polar System (IJPS)] wherein NOAA occupies the early afternoon sun-synchronous orbit of a multiorbit constellation. The complementary orbits are at $\sim 0930$ and 2130 local time [serviced by the European Organisation for the Exploitation of Meteorological Satellites (EUMETSAT)/Meteorological Operational satellites (MetOp)] and $\sim 0530$ and 1730 local time [serviced by the China Meteorological Administration (CMA)/ Fengyun (FY)]. At this spacing, the constellation provides global coverage at $\sim 4$ - $h$ (at the equator, or higher at mid- and high latitudes) revisit time. However, the sensor suite among the various partners is not homogenous, and currently only SNPP and NOAA-20 offer a DNB-like nocturnal measurement.

The potential benefits of higher-temporalresolution nighttime visible observations are wide ranging, and are a compelling prospect for future satellite observing systems. Including a DNB-like instrument in GEO orbit (emphasizing low and midlatitudes), a highly elliptical orbit (HEO; e.g., Molniya or Tundra, emphasizing the high latitudes), or on a larger LEO constellation (e.g., a CubeSat or small-satellite constellation) would enable "weather in motion" capabilities from nocturnal low-light visible observations. It would also provide unique artificial light-change information for tracking, disaster monitoring, and numerous applications tied to the diurnal variation of city lights.

Each satellite orbit mentioned above comes with its own array of technological challenges, from enhanced stray-light mitigation and signal-to-noise challenges from the GEO/HEO perspectives to considerations for multiangle viewing geometries and associated parallax displacement effects in a LEO constellation. Even as the first members of the GOES-R series take flight, planning for the next-generation GOES architecture is under way. Through examples such as Hurricane Matthew and the other major hurricanes of the 2017 season, the DNB continues to make a case for how low-light visible observations help to bridge the nocturnal gap. In terms of situational awareness with and without such information, the differences truly are day and night.

ACKNOWLEDGMENTS. We thank our peer reviewers for the care and attention paid to helping us improve the quality of this manuscript. The support of the NOAA JPSS Program Office, and the Oceanographer of the Navy through the program office at the PEO C4I and Space/ PMW-180 under Program Element PE-0603207N is gratefully acknowledged. We thank Mr. Frankie Lucena for his surface-based photography of nightglow gravity waves and sprites above Hurricane Matthew, and Mr. Walt Lyons for his insight into the properties of sprite geometry.

\section{REFERENCES}

Alexander, M. J., and Coauthors, 2010: Recent developments in gravity-wave effects in climate models and the global distribution of gravity-wave momentum flux from observations and models. Quart. J. Roy. Meteor. Soc., 136, 1103-1124, https://doi.org/10.1002 /qj.637.

Azeem, S. I., J. Yue, L. Hoffmann, S. D. Miller, W. C. Straka III, and G. Crowley, 2015: Multisensor profiling of a concentric gravity wave event propagating from the troposphere to the ionosphere. Geophys. Res. Lett., 42, 7874-7880, https://doi .org/10.1002/2015GL065903.

Bankert, R. L., J. E. Solbrig, T. F. Lee, and S. D. Miller, 2011: Automated lightning flash detection in nighttime visible satellite data. Wea. Forecasting, 26, 399-408, https://doi.org/10.1175/WAF-D-10 $-05002.1$

Cao, C., X. Shao, and S. Uprety, 2013: Detecting light outages after severe storms using the S-NPP/VIIRS day/night band radiances. IEEE Geosci. Remote Sens. Lett., 10, 1582-1586, https://doi.org/10.1109 /LGRS.2013.2262258.

Dewan, E. M., and Coauthors, 1998: MSX satellite observations of thunderstorm-generated gravity waves in mid-wave infrared images of the upper stratosphere. Geophys. Res. Lett., 25, 939-942, https:// doi.org/10.1029/98GL00640.

Elvidge, C. D., K. E. Baugh, V. R. Hobson, E. A. Kihn, and H. W. Kroehl, 1998: Detection of fires and power outages using DMSP-OLS data. Remote Sensing Change Detection: Environmental Monitoring Methods and Applications, R. S. Lunetta and C. D. Elvidge, Eds., Sleeping Bear Press, 123-135.

,-- - M. Zhizhin, F. C. Hsu, and T. Ghosh, 2017: VIIRS night-time lights. Int. J. Remote Sens., 38, 5860-5879, https://doi.org/10.1080/01431161.2017 .1342050 .

Fiolleau, T., and R. Roca, 2013: Composite life cycle of tropical mesoscale convective systems from geostationary and low Earth orbit satellite observations: Method and sampling considerations. Quart. J. Roy. Meteor. Soc., 139, 941-953, https://doi.org/10.1002/qj.2174.

Folmer, M. J., and Coauthors, 2015: Satellite tools to monitor and predict Hurricane Sandy (2012): Current 
and emerging products. Atmos. Res., 166, 165-181, https://doi.org/10.1016/j.atmosres.2015.06.005.

Gentry, R.C., 1955: The 1954 hurricane season. Weatherwise, 8, 12-18, https://doi.org/10.1080/00431672.1955 .9930360 .

Hawkins, J. D., T. F. Lee, J. Turk, C. Sampson, J. Kent, and K. Richardson, 2001: Real-time Internet distribution of satellite products for tropical cyclone reconnaissance. Bull. Amer. Meteor. Soc., 82, 567-578, https://doi.org/10.1175/1520-0477(2001)082<0567: RIDOSP $>2.3 . \mathrm{CO} ; 2$.

— , S. D. Miller, J. E. Solbrig, R. L. Bankert, M. Surrat, and K. A. Richardson, 2017: Tropical cyclone characterization via nocturnal low-light visible illumination. Bull. Amer. Meteor. Soc., 98, 2351-2365, https:// doi.org/10.1175/BAMS-D-16-0281.1.

Hoffmann, L., X. Wu, and M. J. Alexander, 2018: Satellite observations of stratospheric gravity waves associated with rapid intensification of tropical cyclones. Geophys. Res. Lett., 45, 1692-1700, https://doi .org/10.1002/2017GL076123.

Holton, J. R., 1982: The role of gravity wave induced drag and diffusion in the momentum budget of the mesosphere. J. Atmos. Sci., 39, 791-799, https://doi .org/10.1175/1520-0469(1982)039<0791:TROGWI $>2.0 . \mathrm{CO} ; 2$.

Kalluri, S., and Coauthors, 2018: From photons to pixels: Processing data from the Advanced Baseline Imager. Remote Sens., 10, 177, https://doi.org/10.3390 /rs10020177.

Kohiyama, M., H. Hayashi, N. Maki, M. Higashida, H. W. Kroehl, C. D. Elvidge, and V. R. Hobson, 2004: Early damaged area estimation system using DMSP-OLS night-time imagery. Int. J. Remote Sens., 25, 2015-2036, https://doi.org/10.1080 /01431160310001595033.

Landsea, C. W., and J. L. Franklin, 2013: Atlantic hurricane database uncertainty and presentation of a new database format. Mon. Wea. Rev., 141, 3576-3592, https://doi.org/10.1175/MWR-D-12 -00254.1 .

Lyons, W., 2017: Photographing weather in the dark. Weatherwise, 70 (4), 20-27, https://doi.org/10.1080 /00431672.2017.1321923.

Miller, S. D., and R. E. Turner, 2009: A dynamic lunar spectral irradiance dataset for NPOESS/VIIRS Day/Night Band nighttime environmental applications. IEEE Trans. Geosci. Remote Sens., 47, 2316-2329, https://doi.org/10.1109/TGRS.2009 .2012696.

, C. L. Combs, S. Q. Kidder, and T. F. Lee, 2012a: Assessing moonlight availability for nighttime environmental applications by low-light visible polar-orbiting satellite sensors. J. Atmos. Oceanic Technol., 29, 538-557, https://doi.org/10.1175/JTECH -D-11-00192.1.

— S. P. Mills, C. D. Elvidge, D. T. Lindsey, T. F. Lee, and J. D. Hawkins, 2012b: Suomi satellite brings to light a unique frontier of environmental imaging capabilities. Proc. Natl. Acad. Sci. USA, 109, 15 706-15 711, https://doi.org/10.1073/pnas .1207034109 .

— ties of the Suomi National Polar-orbiting Partnership (NPP) Visible Infrared Imaging Radiometer Suite (VIIRS) Day/Night Band. Remote Sens., 5, 6717-6766, https://doi.org/10.3390/rs5126717.

— W. W. Straka III, J. Yue, S. M. Smith, M. J. Alexander, L. Hoffmann, M. Setvák, and P. T. Partain, 2015: Upper atmospheric gravity wave details revealed in nightglow satellite imagery. Proc. Natl. Acad. Sci. USA, 112, E6728-E6735, https://doi.org/10.1073 /pnas.1508084112.

Olander, T. L., and C. S. Velden, 2007: The advanced Dvorak technique: Continued development of an objective scheme to estimate tropical cyclone intensity using geostationary infrared satellite imagery. Wea. Forecasting, 22, 287-298, https://doi.org/10.1175 /WAF975.1.

Román, M., and Coauthors, 2018: NASA’s Black Marble standard product suite. Remote Sens. Environ., 210, 113-143, https://doi.org/10.1016/j.rse.2018.03 .017 .

Schmit, T. J., P. Griffith, M. M. Gunshor, J. M. Daniels, S. J. Goodman, and W. J. Lebair, 2017: A closer look at the ABI on the GOES-R series. Bull. Amer. Meteor. Soc., 98, 681-698, https://doi.org/10.1175/BAMS -D-15-00230.1.

Stewart, S. R., 2017: NHC tropical cyclone report: Hurricane Matthew (AL142016). NOAA/NHC, 96 pp., www.nhc.noaa.gov/data/tcr/AL142016 Matthew.pdf.

Tratt, D. M., and Coauthors, 2018: GHOST: A satellite mission concept for persistent monitoring of stratospheric gravity waves induced by severe storms. Bull. Amer. Meteor. Soc., https://doi.org/10.1175/BAMS -D-17-0064.1, in press.

Velden, C., and Coauthors, 2005: Recent innovations in deriving tropospheric winds from meteorological satellites. Bull. Amer. Meteor. Soc., 86, 205-223, https://doi.org/10.1175/BAMS-86-2-205.

— , and Coauthors, 2006: The Dvorak tropical cyclone intensity estimation technique: A satellitebased method that has endured for over 30 years. Bull. Amer. Meteor. Soc., 87, 1195-1210, https://doi .org/10.1175/BAMS-87-9-1195. 
Willoughby, H. E., F. D. Marks Jr., and R. J. Feinberg, 1984: Stationary and moving convective bands in hurricanes. J. Atmos. Sci., 41, 3189-3211, https://doi.org/10.1175/1520 -0469(1984)041<3189:SAMCBI>2.0.CO;2.

Witmer, F. D. W., and J. O’Loughlin, 2011: Detecting the effects of wars in the Caucasus regions of Russia and Georgia using radiometrically normalized DMSP-OLS nighttime lights imagery. GISci. Remote Sens., 48, 478-500, https://doi.org/10.2747/1548 -1603.48 .4 .478 .

Yue, J., and W. A. Lyons, 2015: Structured elves: Modulation by convectively generated gravity waves.
Geophys. Res. Lett., 42, 1004-1011, https://doi .org/10.1002/2014GL062612.

- and Coauthors, 2009: Concentric gravity waves in the mesosphere generated by deep convective plumes in the lower atmosphere near Fort Collins, Colorado. J. Geophys. Res., 114, D06104, https://doi .org/10.1029/2008JD010894.

- L. L. Hoffmann, and M. J. Alexander, 2013: Simultaneous observations of convective gravity waves from a ground-based airglow imager and the AIRS satellite experiment. J. Geophys. Res. Atmos., 118, 3178-3191, https://doi.org/10.1002/jgrd.50341.

\section{The Thinking Person's Guide to Climate Change}

\section{Robert Henson}

Expanded and updated from Henson's Rough Guide

to Climate Change, 3rd edition (no longer in print), combining years of data with recent research, including conclusions from the Fifth Assessment Report of the Intergovernmental Panel on Climate Change, the Guide breaks down the issues into straightforward categories:

> Symptoms, including melting ice and extreme weather

$>$ Science, laying out what we know and how we know it

$>\quad$ Debates, tackling the controversy and politics

$>$ Solutions and Actions for creating the best possible future
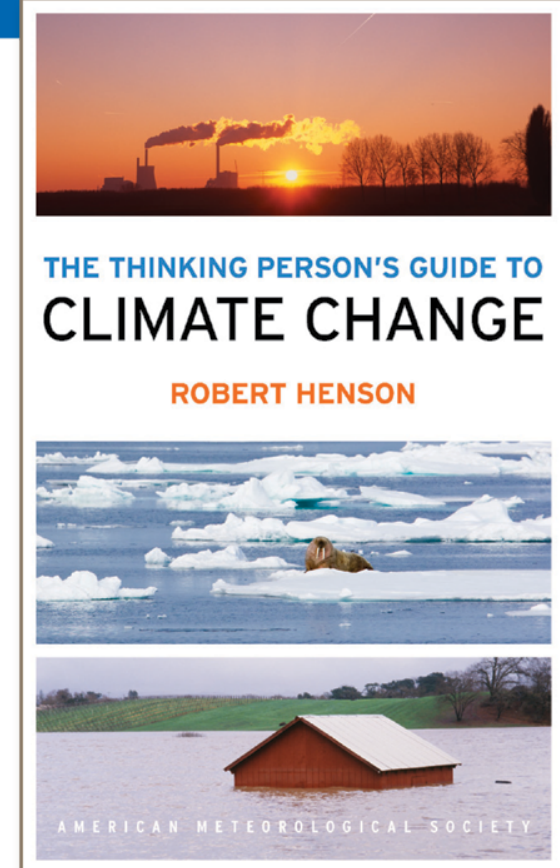